\title{
Article
}

\section{Transformative Use of Additive Technology in Design and Manufacture of Hydraulic Actuator for Fly-by-Wire System}

\author{
Krzysztof Warzocha ${ }^{1, *}$, Jerzy Szura ${ }^{1}$, Piotr Bąk ${ }^{1}$, Paweł Rzucidło ${ }^{2, *(\mathbb{D})}$ and Tomasz Rogalski ${ }^{2}$ (I) \\ 1 Domin, ul. Wojska Polskiego 20, 39-300 Mielec, Poland; jerzy.szura@domin.co (J.S.); piotr.bak@domin.co (P.B.) \\ 2 Faculty of Mechanical Engineering and Aeronautics, Rzeszow University of Technology, al. Powstańców \\ Warszawy 8, 35-959 Rzeszów, Poland; orakl@prz.edu.pl \\ * Correspondence: krzysztof.warzocha@domin.co (K.W.); pawelrz@prz.edu.pl (P.R.)
}

Citation: Warzocha, K.; Szura, J.; Bąk, P.; Rzucidło, P.; Rogalski, T. Transformative Use of Additive Technology in Design and Manufacture of Hydraulic Actuator for Fly-by-Wire System. Appl. Sci. 2021, 11, 4772. https://doi.org/ 10.3390/app11114772

Academic Editor: Stefan Dimov

Received: 23 April 2021

Accepted: 18 May 2021

Published: 22 May 2021

Publisher's Note: MDPI stays neutral with regard to jurisdictional claims in published maps and institutional affiliations.

Copyright: (c) 2021 by the authors. Licensee MDPI, Basel, Switzerland. This article is an open access article distributed under the terms and conditions of the Creative Commons Attribution (CC BY) license (https:// creativecommons.org/licenses/by/ $4.0 /)$.

\begin{abstract}
In this paper, the results of research on additively manufactured aerospace parts made of maraging steel are presented. This state-of-the-art technology seems to have the highest potential for practical use in the field of ultra-light and high-performance aerospace hydraulic parts. The strength properties of representative specimens made with steel 1.2709 were investigated. The researchers conducted static tensile testing, fatigue tensile testing, and pressure impulse testing. A Goodman diagram was plotted to visualize the impact of the building orientation vs. load character on the fatigue strength of the additive manufacturing (AM) specimens. Based on the research carried out on the strength of the AM samples, an aircraft flight control actuator was designed to achieve the highest level of safety integrity along with the greatest simplicity and lowest weight relative to hydraulic actuators manufactured using classical methods. The entire design process was integrated with the manufacturing process to achieve this target.
\end{abstract}

Keywords: additive manufacturing; selective laser melting; maraging steel; mechanical properties; fatigue; hydraulics; aerospace systems; fly-by-wire; FBW; actuators

\section{Introduction}

The actuators used in aircraft flight control systems are most often hydraulic elements [1-3], although in "more electric" [4-6] or "all-electric" aircraft [7,8], electromechanical actuators are also successfully used $[9,10]$. Hybrid servos can also be found in aviation onboard systems [11]. Hydraulic actuators ensure the transmission of very high power in relation to their weight [12], surpassing both electromechanical and pneumatic systems in this respect. The power of hydraulic systems is relatively easy to maintain and control, and properly designed and operated hydraulic systems are extremely reliable and safe [13]. Their structure is strictly defined by standards [14]. The hydraulic controls are automated [15], allowing direct operation, for example, the position of the actuator. The biggest disadvantages of hydraulic systems include the high costs related to the construction of their installation. They also require regular inspection and maintenance, and breakdowns related to the occurrence of leaks in the hydraulic system are particularly troublesome [12]. Designing actuators for control surfaces requires special consideration of the aspects related to their reliability, operational safety, and long-term operation in unfavorable environmental conditions (e.g., large-amplitude changes in ambient temperature, air pressure, and exposure to vibrations and shocks) [13-15]. Hydraulic systems made using classic technologies have long been able to meet these requirements.

In view of current environmental degradation, the rise of fuel prices, and constrained sourcing and gathering of renewable energy, the aerospace industry needs to constantly conduct research on new materials and technologies. Reducing the total weight of an aircraft constitutes one of the most important tasks for contemporary aviation. Decreasing the weight of medium- and long-haul aircraft by $1 \mathrm{~kg}$ enables saving up to 150 liters of fuel per year [16]. Therefore, since fire-resistant oils based on phosphoric esters (e.g., 
Skydrol or HyJet [17]) are more lightweight than mineral oils by up to $7 \%$, they have been applied in the field of hydraulic systems for several years. Despite research conducted on ways to increase the endurance of the most frequently applied aluminum, titanium, and stainless steel alloys used in the components of aircraft hydraulics, reducing the weight of mechanical components is considerably more difficult. It is estimated that the value of every reduced kilogram of the weight of an aircraft may be anything from USD 100 to USD 2000 [18]. In the context of reducing the weight of the aircraft, and thus reducing fuel consumption, $\mathrm{CO}_{2}$ emissions, harmful substances, and noise emissions, taking actions related to the design, production, and implementation of lighter actuators realized in additive technology seems to be the right thing to do. This is also confirmed by the attempts being made by major producers in the aviation market [19]. The potential for the application of additive technologies in aircraft looks promising, and machine producers already have devices dedicated to metal printing that may be used to manufacture parts on an industrial scale [20-22].

The Domin company, in cooperation with Rzeszów University of Technology, conducted extensive research on the endurance of maraging steel 1.2709 as far as the process of laser melting is concerned (the actual research of SLM technology in relation to maraging steel 1.2709 is also described in the work of other teams [23,24]). Furthermore, researchers have assessed whether the material in question may be used in aircraft for hydraulic components [25]. Hydraulic actuators have a highly complex internal structure, especially regarding operating conditions. Such a structure is particularly noticeable in a characteristic of the actuator presented in this paper and dedicated to the fly-by-wire (FBW) control system. Due to the lack of direct mechanical connection between the inceptors (steering wheel and mini side-stick) and the actuators of the control surfaces, FBW systems require very high reliability and there must also be multiple (redundant) systems [26-30]. In this study, it was of interest to investigate the mechanical properties of additive manufacturing (AM) samples produced by SLM and the potential of the application of this technology in the design and manufacture of hydraulic components for aerospace. A previous study carried out on the design of the presented actuator demonstrated the performance of maraging steel sleeves produced by SLM with subsequent age hardening [25]. This paper presents the extended results of mechanical tests of SLM samples, including tensile fatigue and pressure fatigue tests (Sections 2 and 3). The Goodman diagram [31,32] developed based on the fatigue test results for the design of elements made of AM maraging steel is also presented at the end of Section 3. Section 4 presents the structure of the actuator and photographs showing selected stages of the implementation of an element in SLM technology. This section also presents a working prototype of an actuator made with AM technology.

\section{Mechanical Properties of Maraging Steels}

High-strength maraging steels constitute a special class of low-carbon iron-nickel alloys with a martensitic structure hardened by precipitates. The main alloying elements to which this steel owes its strength and ductility are $\mathrm{Ni}, \mathrm{Co}$, and $\mathrm{Mo}$ [33]. In industry, the most commonly used maraging steels are those with $18 \%$ nickel content. This element increases hardenability, enabling martensitic transformation during air-cooling, and increases resistance to fracture. Cobalt reduces the solubility of molybdenum, which greatly increases the ductility of steel and allows the addition of other elements that strengthen the structure of the material, primarily titanium. Table 1 shows the most popular maraging steels. 
Table 1. Chemical composition of the most popular maraging steels [33-35].

\begin{tabular}{ccccccc}
\hline \multirow{2}{*}{ Grade } & \multicolumn{2}{c}{ Wrought } & \multicolumn{2}{c}{ Cast } & \multicolumn{2}{c}{ AM Powder } \\
\cline { 2 - 7 } & $\mathbf{1 8 N i 1 4 0 0}$ & $\mathbf{1 8 N i 1 7 0 0}$ & $\mathbf{1 8 N i 1 9 0 0}$ & $\mathbf{1 8 N i 2 4 0 0}$ & $\mathbf{1 7 N i 1 6 0 0}$ & M300/1.2709 \\
\hline $\begin{array}{c}\text { Nominal 0.2\% Proof } \\
\text { Stress (MPa) }\end{array}$ & $\mathbf{1 4 0 0}$ & $\mathbf{1 7 0 0}$ & $\mathbf{1 9 0 0}$ & $\mathbf{2 4 0 0}$ & $\mathbf{1 6 0 0}$ & $\mathbf{1 8 0 0}$ \\
\hline $\mathrm{Ni}$ & $17-19$ & $17-19$ & $18-19$ & $17-18$ & $16-17.5$ & $17-19$ \\
$\mathrm{Co}$ & $8.0-9.0$ & $7.0-8.5$ & $8.0-9.5$ & $12-13$ & $9.5-11.0$ & $8.5-9.5$ \\
Mo & $3.0-3.5$ & $4.6-5.1$ & $4.6-5.2$ & $3.5-4.0$ & $4.4-4.8$ & $4.5-5.2$ \\
Ti & $0.15-0.25$ & $0.3-0.5$ & $0.5-0.8$ & $1.6-2.0$ & $0.15-0.45$ & $0.6-0.8$ \\
Al & $0.05-0.15$ & $0.05-0.15$ & $0.05-0.15$ & $0.1-0.2$ & $0.02-0.1$ & $0.05-0.15$ \\
Si max. & 0.12 & 0.12 & 0.12 & 0.1 & 0.1 & 0.1 \\
Mn max. & 012 & 0.12 & 0.12 & 0.1 & 0.1 & 0.1 \\
C max. & 0.03 & 0.03 & 0.03 & 0.01 & Balance \\
Fe & Balance & Balance & Balance & Balance & Balance \\
\hline
\end{tabular}

The heat treatment of maraging steel requires annealing at a temperature of $800-900{ }^{\circ} \mathrm{C}$ and air-cooling, allowing the attainment of a hardness of $55 \mathrm{HRC}$ and a maximum withstandable stress $R_{m}$ from $1700 \mathrm{MPa}$ to $2400 \mathrm{MPa}$ [34]. Furthermore, the strongest maraging steels achieve their endurance limit at approximately $900 \mathrm{MPa}$ for $\mathrm{R}=0.1$, where $\mathrm{R}$ is the minimum peak stress divided by the maximum peak stress [34].

\section{Verification of the Strength of Age-Hardened Maraging Steel Samples Produced with SLM Technology}

\subsection{Tensile Testing}

The static tensile test was performed using an Instron 3382 machine. The tests were carried out on 10 samples of circular cross section with a nominal initial diameter of $\mathrm{d}_{0}=$ $6 \mathrm{~mm}$, a nominal length of the measuring section of $\mathrm{l}_{0}=25 \mathrm{~mm}$, and an as-built surface finish of Ra 5-12 $\mu \mathrm{m}$. Each sample had a unique name, for example, P1/128/01, etched on by a laser machine. The samples were printed by an SLM 250 machine with a $50 \mu \mathrm{m}$ layer thickness setup. The tests were carried out at room temperature according to the standard PN-EN ISO 6892-1: 2016-09. The test results are presented in Table 2. When analyzing the obtained results, it was observed that the elongation under fracture (parameter $A$ ) varied from $1.2 \%$ to $6.9 \%$, while diameter reduction (parameter $Z$ ) varied between $5 \%$ and $21 \%$. The parameter $R_{0.2}$ is the $0.2 \%$ offset yield strength. Additionally, for some samples, the curves of the change in internal stress in the sample as a function of strain were recorded (Figure 1).

Table 2. Tensile testing results.

\begin{tabular}{ccccc}
\hline Sample No. & $\boldsymbol{R}_{\mathbf{0 . 2}} \mathbf{( M P a )}$ & $\boldsymbol{R}_{\boldsymbol{m}} \mathbf{( M P a )}$ & $\boldsymbol{A} \mathbf{( \% )}$ & $\boldsymbol{Z} \mathbf{( \% )}$ \\
\hline $\mathrm{P} 1 / 128 / 01$ & 1317 & 1432 & 2.9 & 18 \\
$\mathrm{P} 1 / 128 / 02$ & 1359 & 1450 & 5.1 & 21 \\
$\mathrm{P} 1 / 128 / 03$ & 1445 & 1530 & 4.4 & 21 \\
$\mathrm{P} 1 / 128 / 04$ & 1309 & 1397 & 1.2 & 5 \\
$\mathrm{P} 1 / 128 / 05$ & 1530 & 1603 & 2.8 & 13 \\
$\mathrm{P} 1 / 128 / 06$ & 1338 & 1417 & 6.8 & 10 \\
$\mathrm{P} 1 / 128 / 07$ & 1268 & 1336 & 2.8 & 5 \\
$\mathrm{P} 1 / 128 / 08$ & 1259 & 1347 & 6.0 & 6 \\
$\mathrm{P} 1 / 128 / 09$ & 1204 & 1287 & 4.8 & 8 \\
$\mathrm{P} 1 / 128 / 10$ & 1442 & 1514 & 6.9 & 13 \\
\hline
\end{tabular}




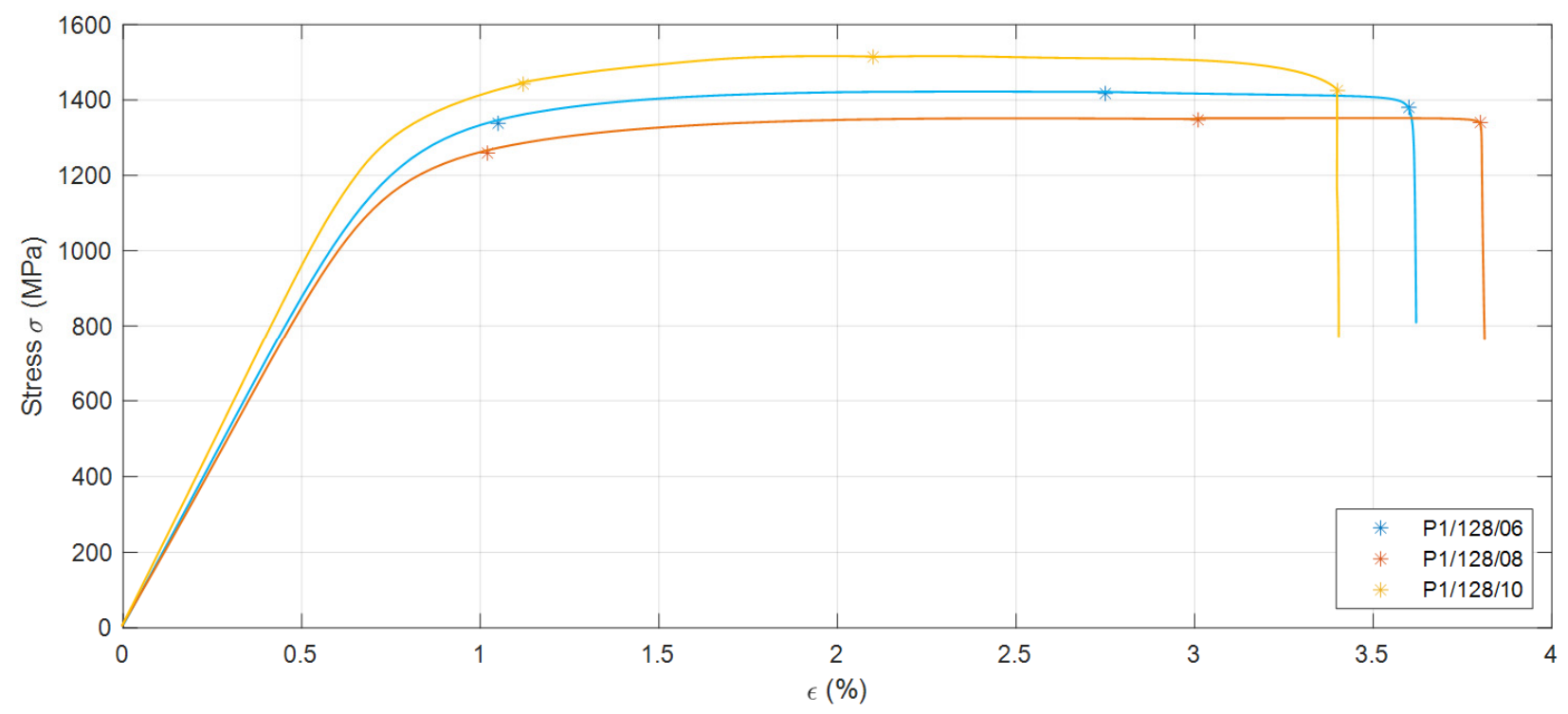

Figure 1. Tensile stress-strain curves.

Comparing the obtained results with the technical specifications of maraging steels produced in a conventional manner, the tensile strength of the printed samples in this case was comparable to that of $18 \mathrm{Ni1400}$ and approximately $16 \%$ lower than that of $18 \mathrm{Ni1700}$.

\subsection{Tensile Fatigue Testing}

Fatigue tests were carried out using an Instron 8801 machine (Figure 2) on samples of circular cross section with an as-built surface finish and a $50 \mu \mathrm{m}$ layer setup, the shapes and dimensions of which were in accordance with the ASTM E466-15 standard. The build orientation of the specimens was 0 degrees with respect to the sample's longitudinal axis. The tests were carried out at room temperature with a cyclically changing load at a frequency $\mathrm{f}=3 \mathrm{~Hz}$. The stresses arising in the sample were defined as one-sided tension with a cycle asymmetry $R=0.05$. The results of measured minimum stress $\sigma_{\min }$ and maximum stress $\sigma_{\max }$ in the sample for fatigue life $\left(\mathrm{N}_{\mathrm{f}}\right)$ are presented in Table 3 . These parameters were used to determine the $\mathrm{S}-\mathrm{N}$ curve (Figure 3).
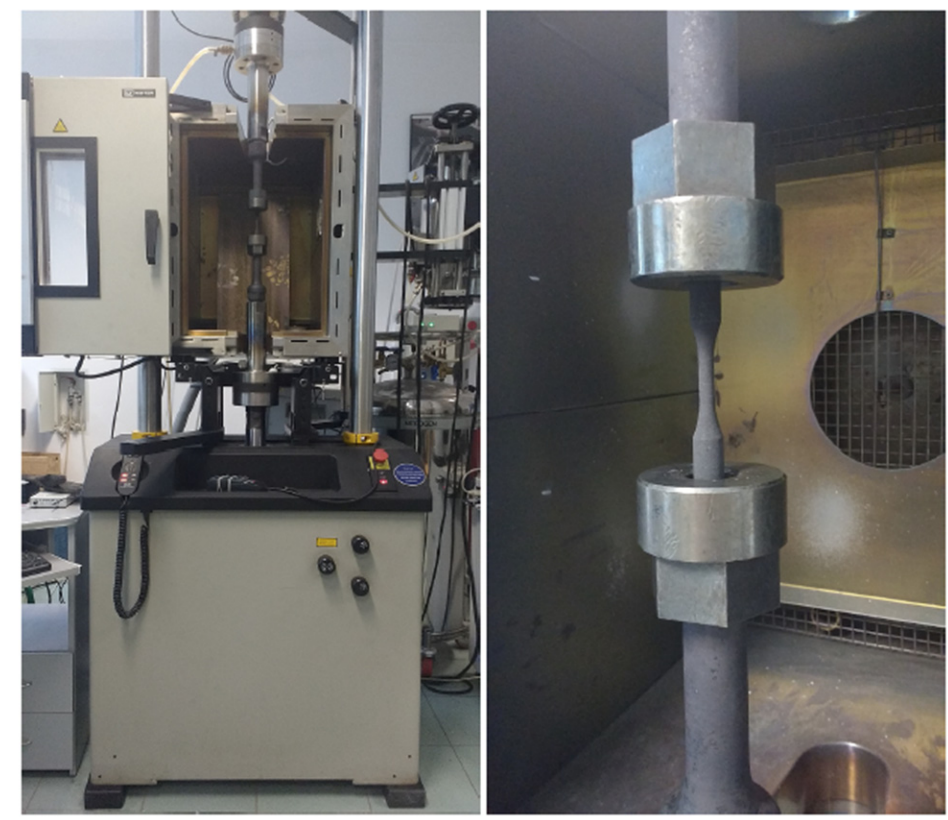

Figure 2. The laboratory test rig Instron 8801. 
Table 3. Tensile fatigue test results.

\begin{tabular}{cccc}
\hline Sample No. & $\boldsymbol{\sigma}_{\max }(\mathbf{M P a})$ & $\boldsymbol{\sigma}_{\min }(\mathbf{M P a})$ & $\boldsymbol{N}_{f}($ Cycles $)$ \\
\hline $\mathrm{R} 1 / 128 / 01$ & 1200 & 60 & 216 \\
$\mathrm{R} 1 / 128 / 02$ & 1000 & 50 & 1237 \\
$\mathrm{R} 1 / 128 / 03$ & 800 & 40 & 3504 \\
$\mathrm{R} 1 / 128 / 04$ & 600 & 30 & 22,077 \\
$\mathrm{R} 1 / 128 / 05$ & 450 & 22.5 & 31,324 \\
$\mathrm{R} 1 / 128 / 06$ & 300 & 15 & 47,489 \\
$\mathrm{R} 1 / 128 / 07$ & 250 & 12.5 & 111,361 \\
$\mathrm{R} 1 / 128 / 08$ & 210 & 10.5 & $300,000 *$ \\
$\mathrm{R} 1 / 128 / 09$ & 200 & & $300,000 *$ \\
\hline
\end{tabular}

*- unbroken samples

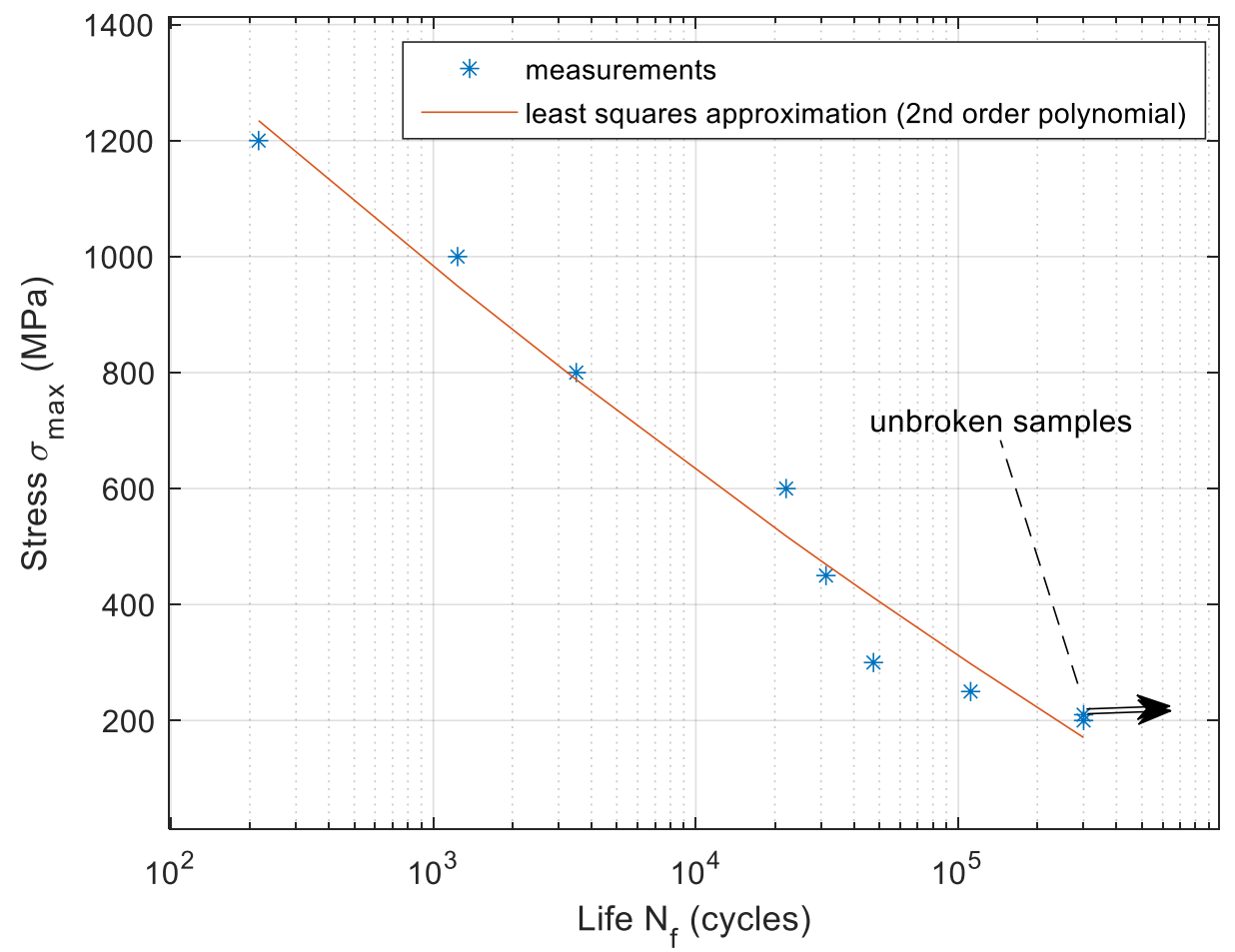

Figure 3. The $\mathrm{S}-\mathrm{N}$ curve for additively manufactured maraging steel, $\mathrm{R}=0.05$.

Comparison of the obtained results with the literature data revealed that the samples made with the additive technologies were damaged at a much lower load. Based on the test results at 300,000 cycles, it can be concluded that the AM samples were approximately $16 \%$ less resistant to fatigue compared with the weakest maraging steels.

\subsection{Pressure Fatigue Testing}

The pressure fatigue tests were carried out on a test rig (Figure 4). The internal diameters of the samples (Figure 5) were 22, 27, and $33 \mathrm{~mm}$ and the wall thicknesses were $0.4,0.5$, and $0.6 \mathrm{~mm}$. The build orientation of the sleeves was 0 degrees with respect to the sample's rotational axis. The samples were sandblasted and machined to achieve good sealing surfaces, leaving the internal and external cross sections in the middle with an as-built surface finish and a $50 \mu \mathrm{m}$ layer setup. The samples were placed in a steel block in the test chamber of the rig. On the basis of the measurement of the hydraulic oil pressure, the cylindrical stresses were determined using the following relationship:

$$
\sigma_{\theta}=\frac{P d}{2 t}
$$


where $\sigma_{\theta}$ is cylindrical stress, $P$ is pressure, $d$ is internal diameter, and $t$ is wall thickness.

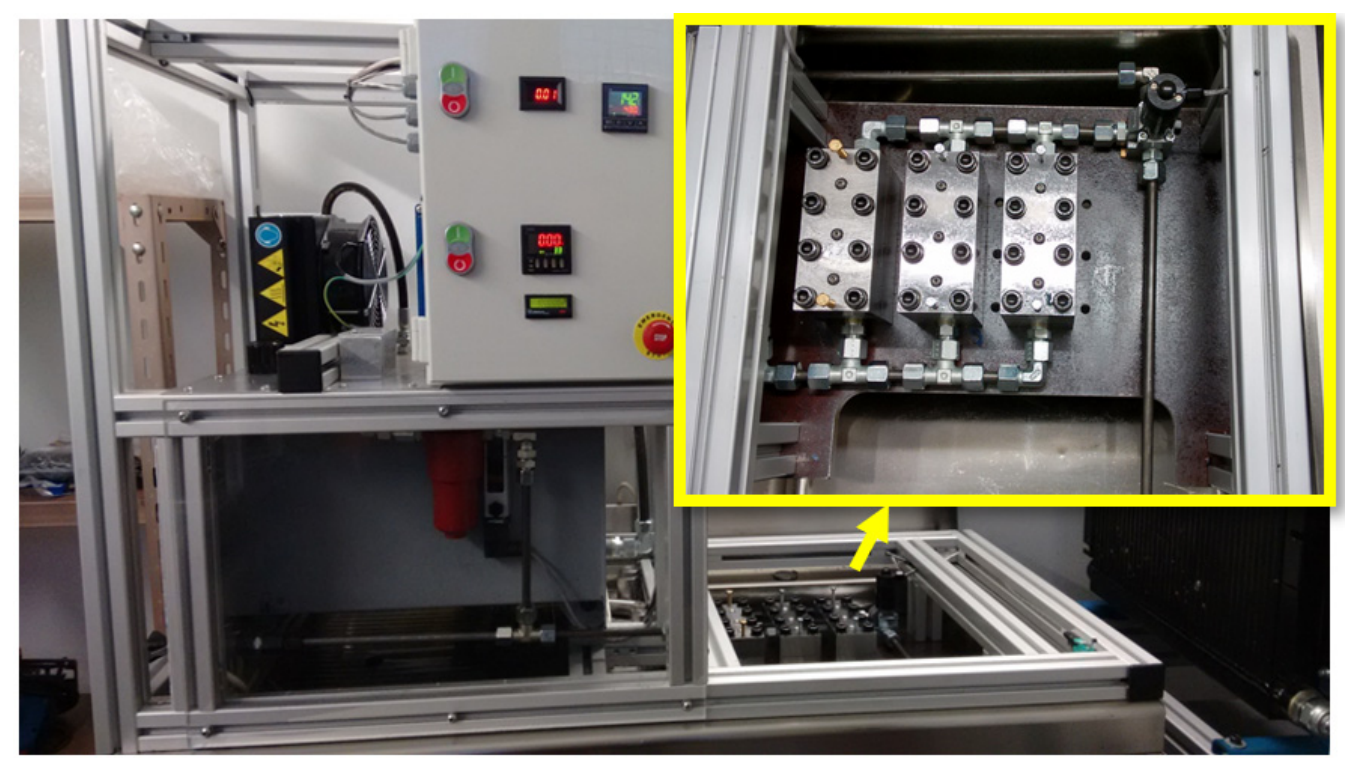

Figure 4. The pressure fatigue test rig.

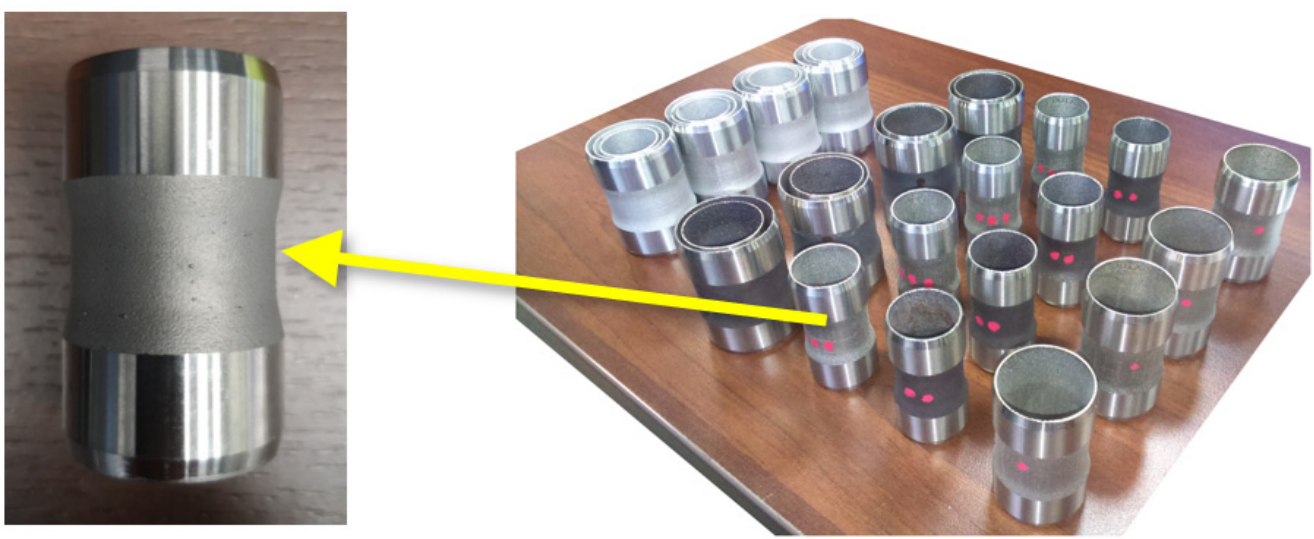

Figure 5. Pressure fatigue samples.

The stresses arising in the sample were controlled by the maximum values of the pressure pulses (Figure 6) at a frequency $\mathrm{f}=5 \mathrm{~Hz}$. The control system counted the pressure pulses until the sample was broken. The results of the pressure fatigue tests are presented in Table 4. Based on Table 4, the S-N curve was created (Figure 7). The pressure fatigue endurance limit was more than $50 \%$ higher in comparison with tensile tests of the AM samples. 


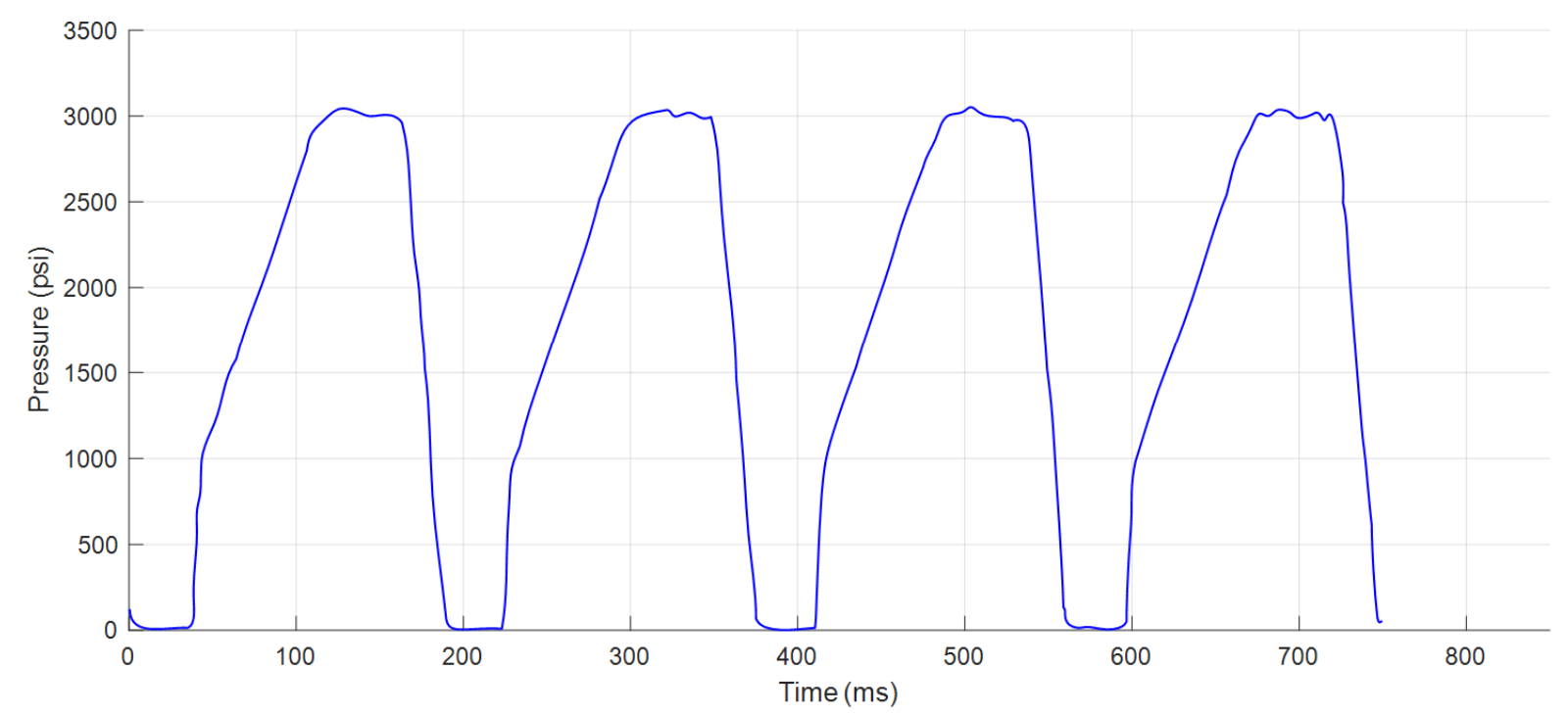

Figure 6. Pressure impulse waveform.

Table 4. Pressure fatigue test results.

\begin{tabular}{ccccc}
\hline Sample No. & $\boldsymbol{t}(\mathbf{m m})$ & $\boldsymbol{P}(\mathbf{p s i})$ & $\boldsymbol{\sigma}_{\max }(\mathbf{M P a})$ & $\boldsymbol{N}_{f}(\mathbf{C y c l e s})$ \\
\hline X0937 & 0.4 & 2900 & 592 & 15,052 \\
X0938 & 0.4 & 3600 & 735 & 20,452 \\
X0939 & 0.4 & 2200 & 449 & 52,125 \\
X0940 & 0.4 & 4895 & 1000 & 4474 \\
X0941 & 0.4 & 1375 & 281 & $1,000,000 *$ \\
X0942 & 0.4 & 1700 & 347 & $1,000,000 *$ \\
X0949 & 0.5 & 1375 & 276 & $1,000,000^{*}$ \\
X0950 & 0.5 & 1600 & 321 & $1,000,000^{*}$ \\
X0951 & 0.5 & 1850 & 371 & 301,249 \\
X0952 & 0.5 & 2600 & 521 & 88,639 \\
X0953 & 0.5 & 2250 & 451 & 99,572 \\
X0954 & 0.5 & 3000 & 601 & 40,106 \\
X0961 & 0.6 & 1375 & 293 & $1,000,000 *$ \\
X0962 & 0.6 & 1600 & 341 & $1,000,000 *$ \\
X0963 & 0.6 & 1850 & 394 & 278,403 \\
X0964 & 0.6 & 2600 & 554 & 119,877 \\
X0965 & 0.6 & 4050 & 863 & 2920 \\
X0966 & 0.6 & 2816 & 600 & 89,037 \\
\hline *- & & & &
\end{tabular}




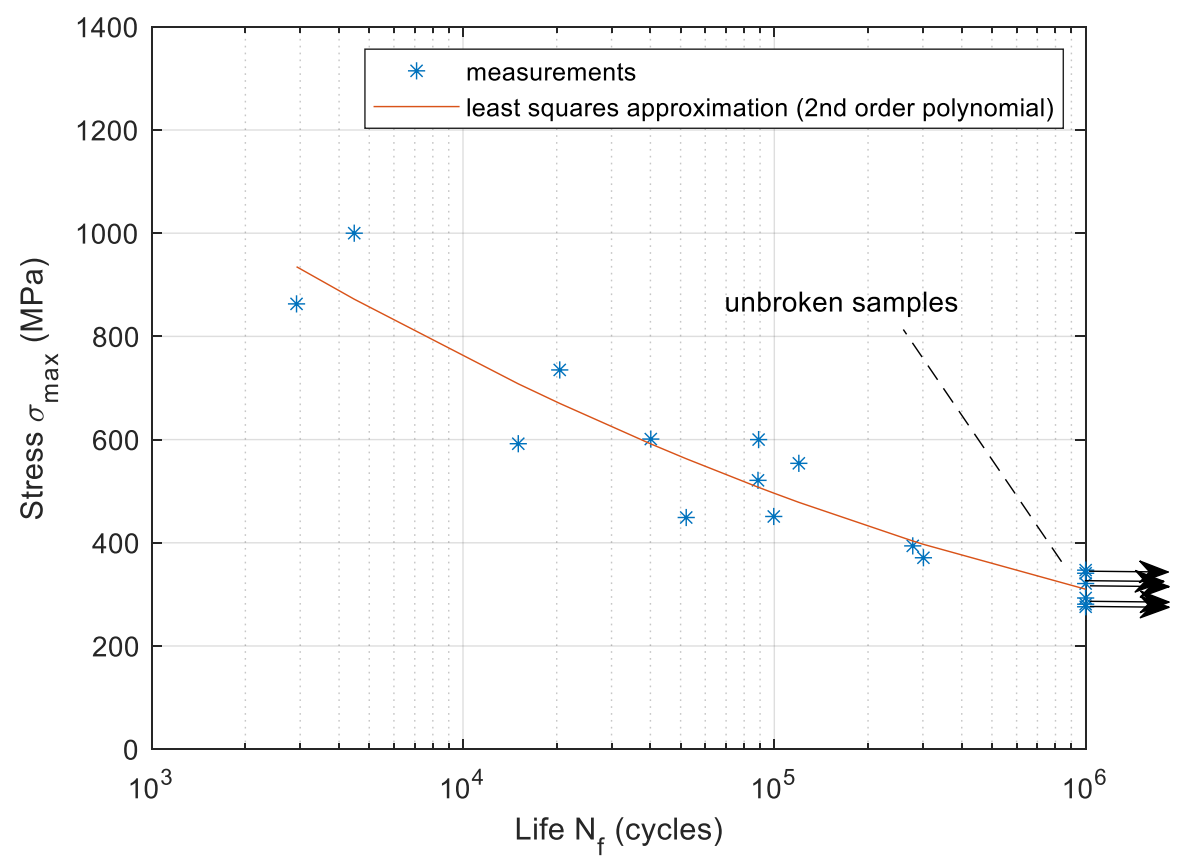

Figure 7. The S-N curve for AM maraging steel for pressure fatigue load, $\mathrm{R}=0$.

\subsection{Goodman Diagram for Designing AM Maraging Steel Components for Fatigue}

The data from the tensile and fatigue testing were used to plot the Goodman diagram as a reference for engineers who are involved in additive manufacturing design processes. The yield strength, ultimate strength, and endurance limit points were calculated in Table 5 and plotted in Figure 8.

Table 5. Calculated material data.

\begin{tabular}{ccc}
\hline Mechanical Data & Average Stress Values & Maximal Error \\
\hline Yield strength & $1347 \mathrm{MPa}$ & $13 \%$ \\
\hline Ultimate strength & $1431 \mathrm{MPa}$ & $12 \%$ \\
\hline Tensile fatigue strength, mean, $\mathrm{R}=0.05$ & $97 \mathrm{MPa}$ & $8 \%$ \\
\hline Pressure fatigue strength, mean, $\mathrm{R}=0$ & $155 \mathrm{MPa}$ & $11 \%$ \\
\hline
\end{tabular}

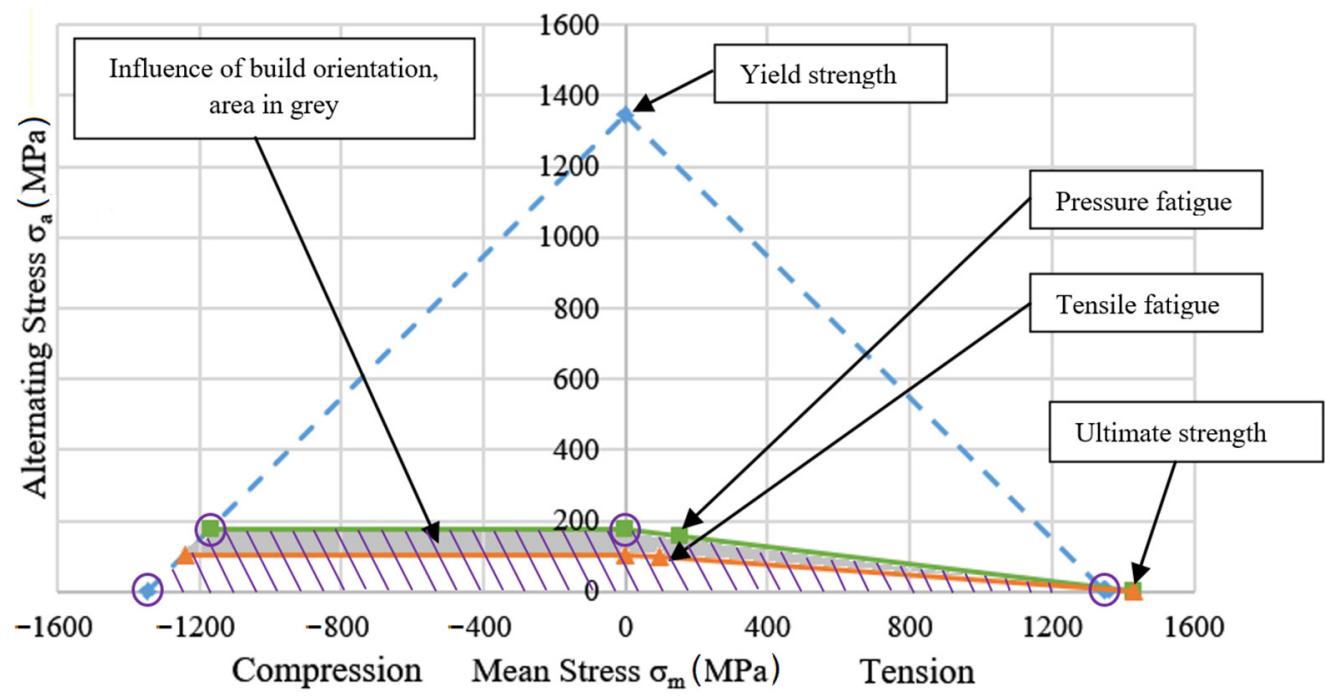

Figure 8. Goodman diagram obtained from fatigue and static testing of the maraging steel specimens produced by SLM. 
The Goodman diagram shows the influence of build orientation on the fatigue properties. AM parts that were loaded in the same direction as the build orientation indicated lower fatigue strength. This effect is widely known in AM technology, and has been extensively analyzed in the literature [36-39]; however, the diagram presented in Figure 8 is the quantitative result obtained by the authors of the work in relation to the selected material and technology in which the presented actuators are made.

\section{The Use of SLM Technology in the Production of Aviation Hydraulic Parts}

\subsection{The Process of Manufacturing and Integrating the Hydraulic Actuator}

Based on the research carried out on the strength of the AM samples, the aircraft flight control actuator was designed to achieve the highest level of safety integrity along with the greatest simplicity and lowest weight. The architecture aims to simplify the methods of failure detection, which need to be included within the flight control computer [31-43]. The general schematic of the flight control actuator (FCA) is presented in Figure 9. The servo actuator system is a dual tandem configuration with a hydro-mechanical anti-jam mechanism. It has two direct-drive servo valves with mechanical feedback linkage from the main ram to the secondary outer sleeve of the servo valve.

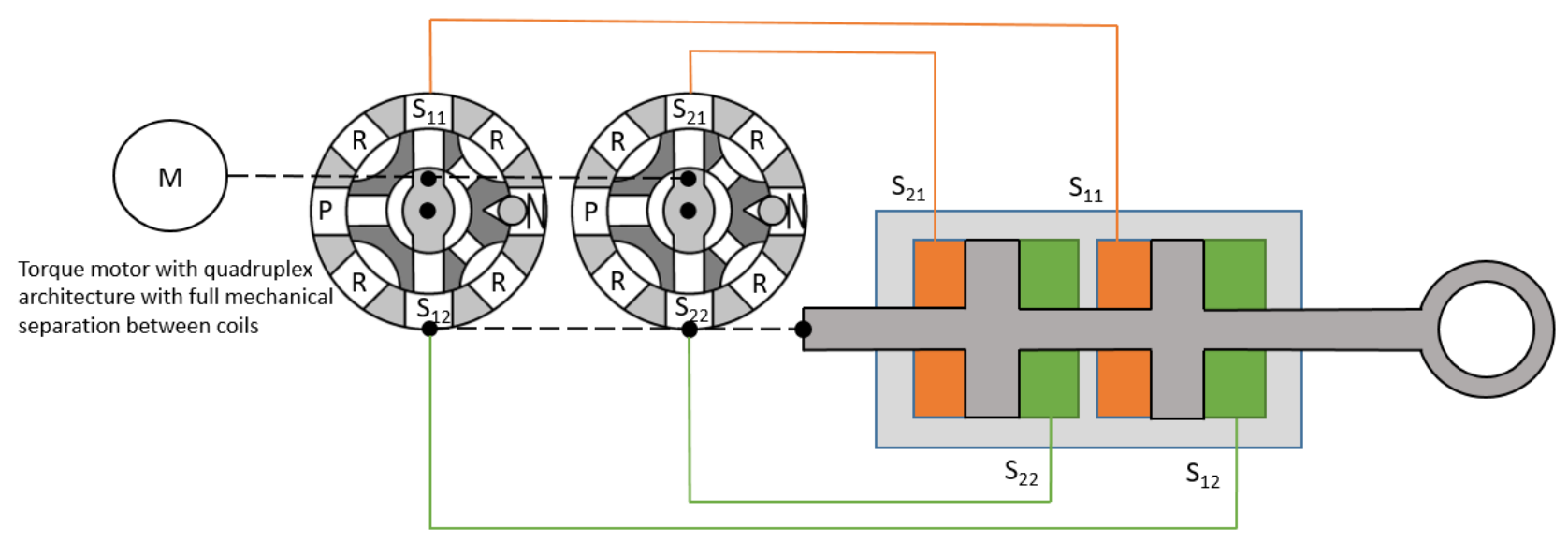

Figure 9. General schematic drawing of the FCA; own drawing based on patent [40] and Domin company materials [41].

The center manifold is a key part of the actuator. It contains a rotary torque motor, two rotary spools, two sleeves, and position sensors coupled on one shaft. The electronic system is a fully quadruplex architecture and is fail operational even in the event of three failures. It includes a redundant three-phase channel motor with independent drives for each control lane. Each of the stator sectors is mechanically separated and capable of driving the load of the rotor in the event of failure. All hydraulic elements inside the valve are pressure- and flow-balanced in order to achieve low friction and hysteresis. The servo valve cross section schema is presented in Figure 10.

A dual hydraulic arrangement with independent valves allows one failure-either mechanical or hydraulic - without performance loss. The actuator receives four electrical command signals and two hydraulic supplies. The actuator can produce ram displacement in response to electrical command signals and continue operation after the failure of any input or internal part.

FCAs are complex items. The use of AM technology has significantly influenced the design and manufacture of many complex components included within the assembly of the actuator to meet the rigorous safety-critical requirements. Selected elements of FCAs manufactured by AM technology and the full assembly of the complete actuator are presented in Figures 11-14. The presented FCA is lighter and has fewer parts [42]. It is approximately half the weight of the equivalent mechanical servo and less than half the weight of any FBW alternative. 


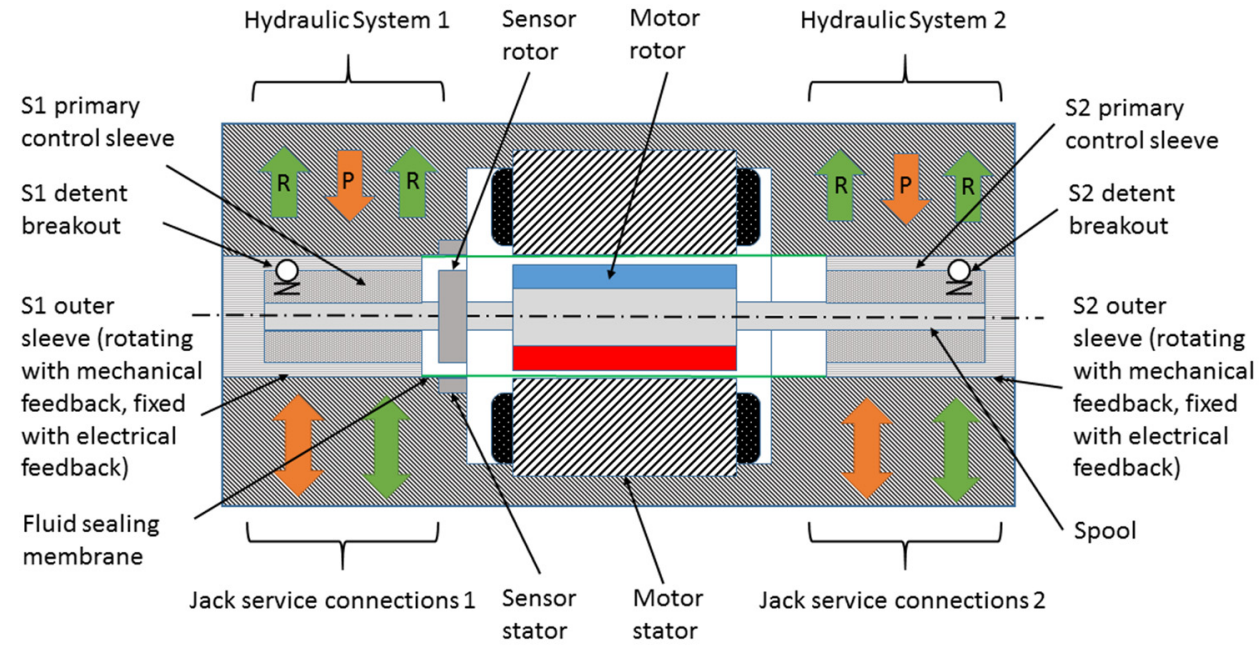

Figure 10. General schematic of the servo; own drawing based on patent [40] and Domin company materials [41].

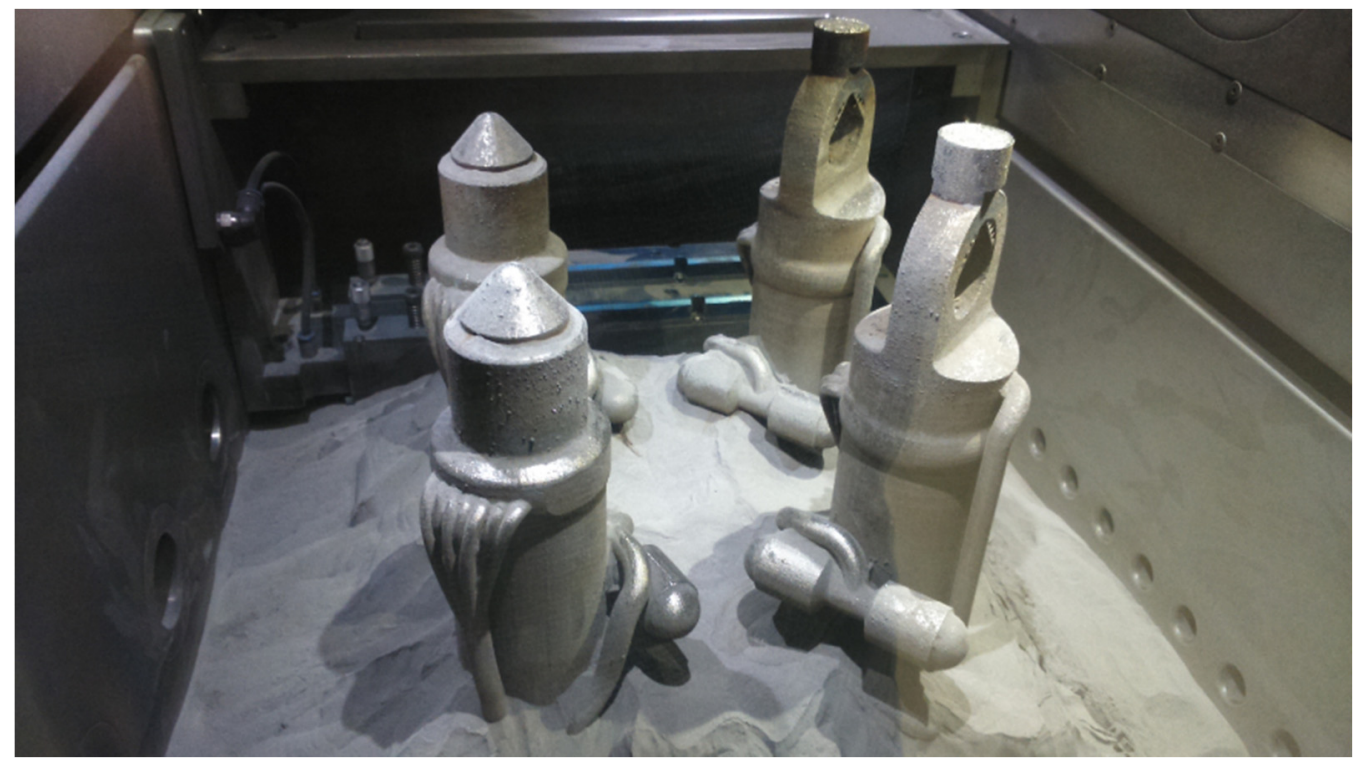

Figure 11. Manufacturing of actuator bodies with AM technology.

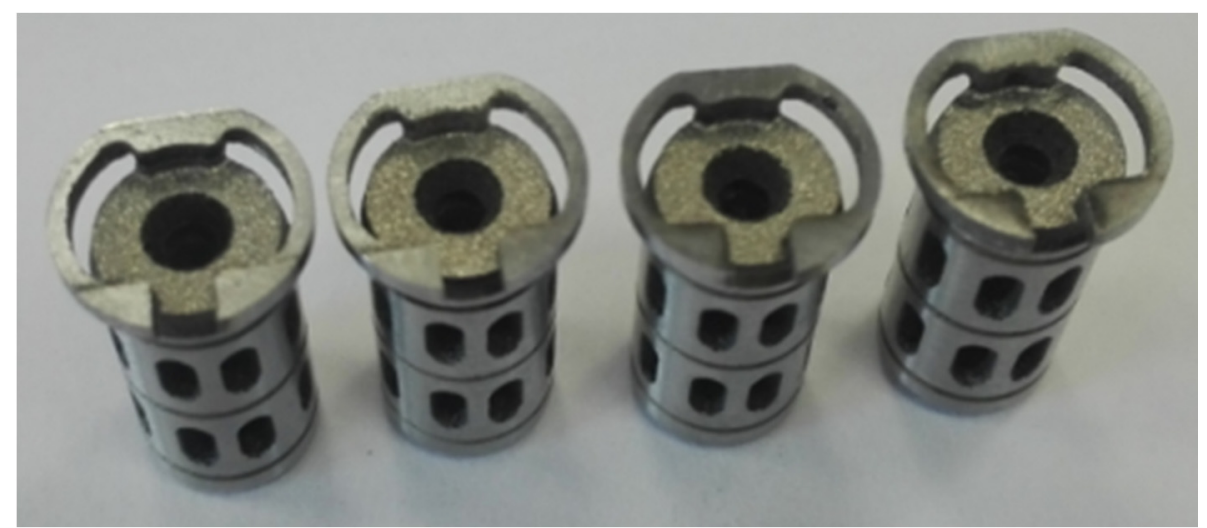

Figure 12. Actuator components made with AM technology ready for integration: primary control sleeves. 


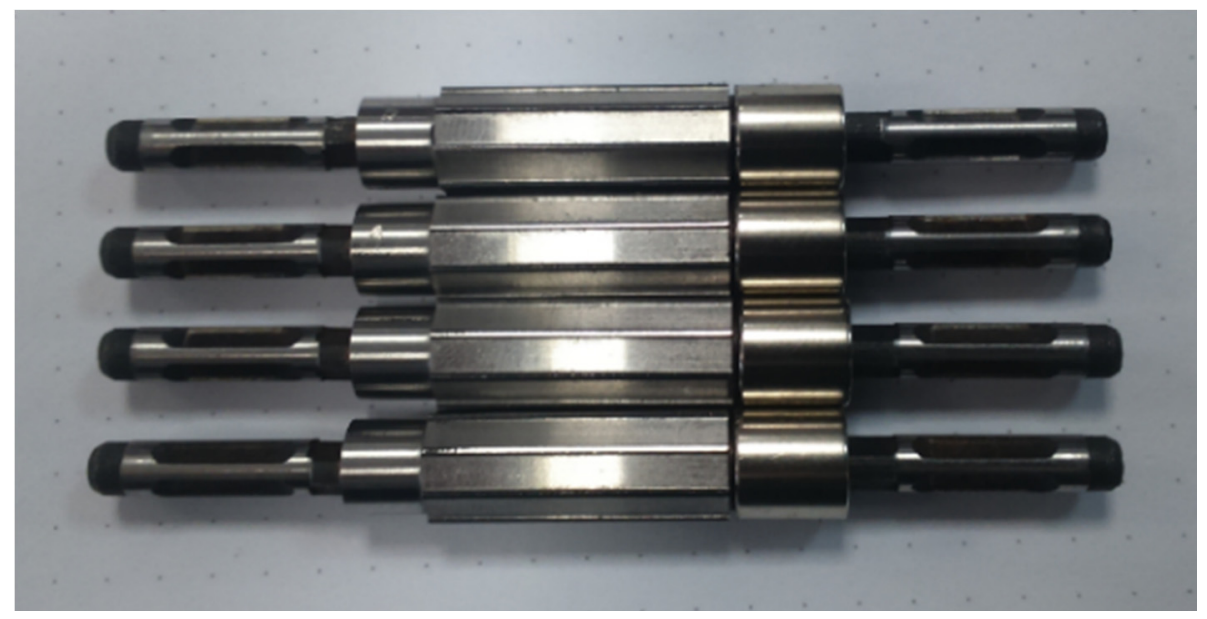

Figure 13. Actuator components made with AM technology ready for integration: primary control spools.

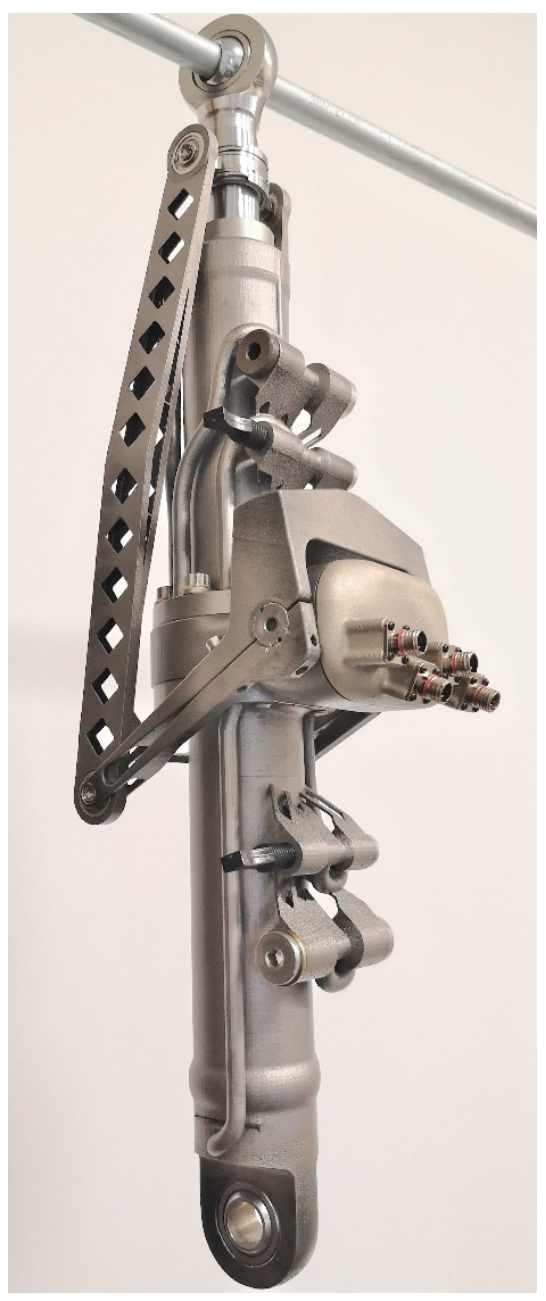

Figure 14. Assembled fly-by-wire actuator manufactured with AM technology.

\subsection{Results of the Preliminary Dynamic Tests}

The complete mechanical prototype of the actuator was prepared for initial dynamic tests (Figure 15). These tests were performed with an operating pressure limited to $100 \mathrm{bar}$. A dedicated electro-mechanism was used for the positioning of the piston rod, together with a proprietary control and measuring system. The obtained actuator responses to the 
step input and the sawtooth input are shown in Figures 16 and 17. The analysis of the step characteristic shows that with the limited working pressure, the actuator movement speed was approximately $75 \mathrm{~mm} / \mathrm{s}$ (the full range of movement is $140 \mathrm{~mm}$ ). For a sawtooth excitation, the delay was tens of milliseconds and the error in the actuator dynamic response was not greater than $7.5 \mathrm{~mm}$ (Figure 17). Detailed and complete tests of the actuators will be possible only after the completion of the work related to the dedicated control system. The development of an actuator control system is a complex and interdisciplinary issue. The effective dynamics of the actuator in its final form will result from both its mechanical properties and the properties of the controller itself.

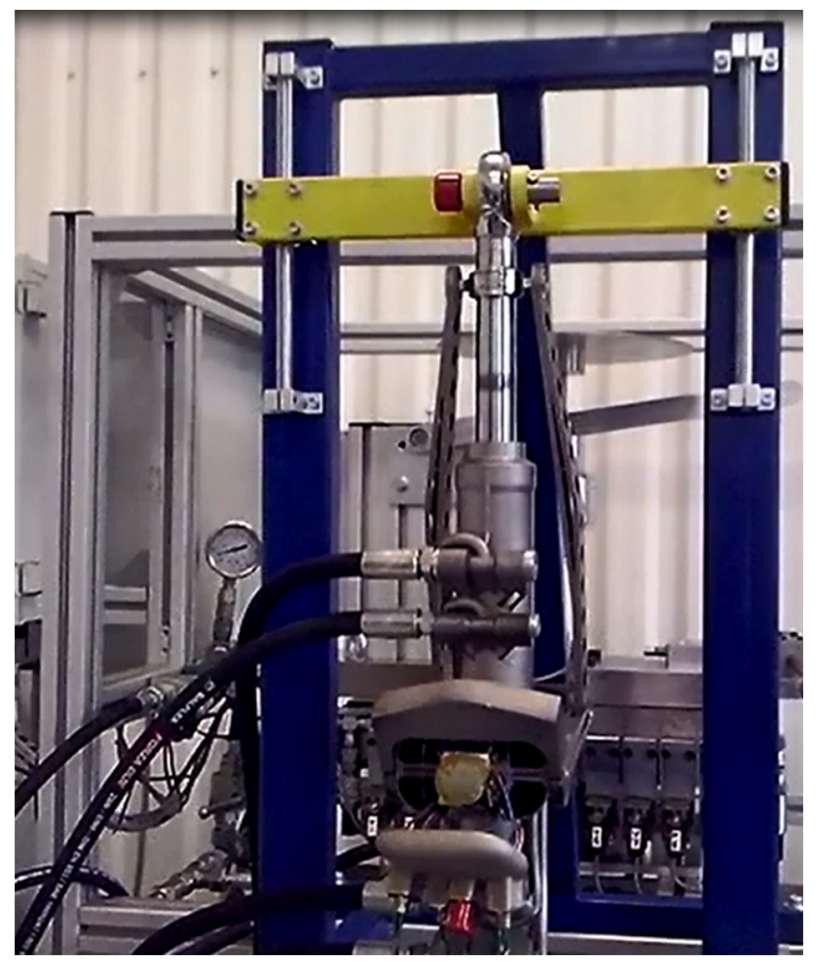

Figure 15. The actuator prototype prepared for preliminary functional tests.

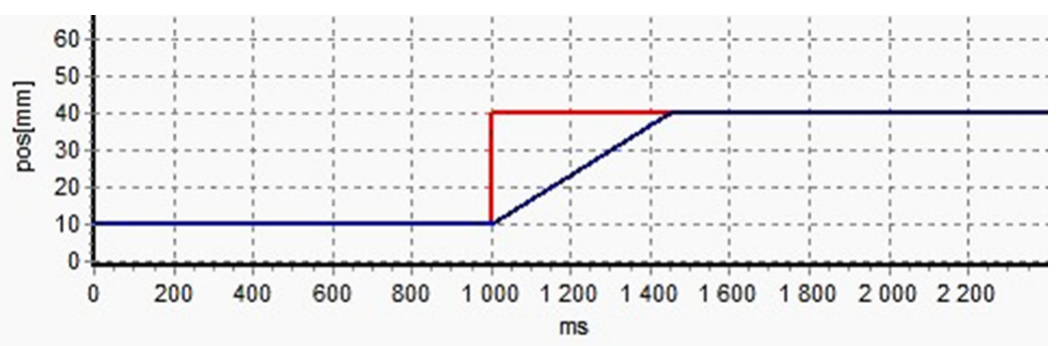

Figure 16. The actuator response to the step input. 

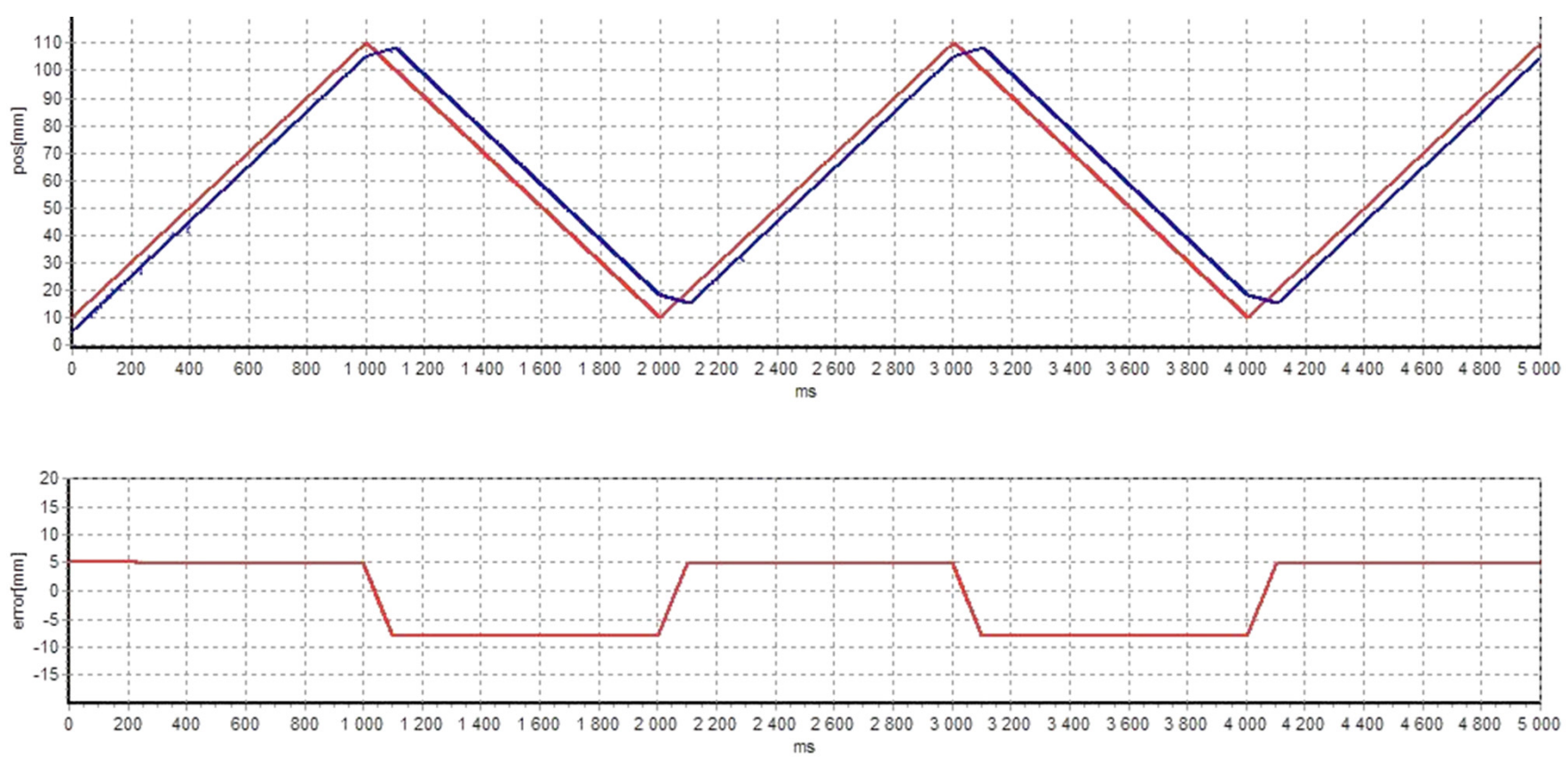

Figure 17. The actuator response to a triangle-shaped input.

\section{Conclusions}

This study investigated the use of SLM technology in the production of aviation hydraulic parts. The results of the static tensile tests indicated that parts produced by SLM achieved similar tensile strength to the maraging steel $18 \mathrm{Ni1} 400$ produced in a conventional manner. Comparison of the tensile fatigue results with the literature data revealed that the samples made with the additive technologies were broken at a lower load. Based on the test results at 300,000 cycles, it can be concluded that the AM samples are approximately $16 \%$ less resistant to fatigue compared with the weakest maraging steels.

A Goodman diagram was plotted to visualize the impact of the building orientation vs. the load character on the fatigue strength of the AM specimens. Directions of load, stress, and building orientation in the samples tested for tensile fatigue were 0 degrees with respect to the specimen's longitudinal axis, and these specimens achieved a lower number of cycles to failure in comparison with pressure fatigue specimens. In contrast to the tensile testing, the pressure acting on the internal wall of the sleeves generated circumferential hoop stresses at 90 degrees to the specimen's build direction. The analysis of the fatigue tests shows that the fatigue limit cannot be strictly determined and is highly dependent on the load vs. the built direction. These findings are consistent with other research and relevant literature $[24,44]$.

The application of additive technologies in aviation may completely redefine the design and manufacture of advanced hydraulic aircraft control systems; however, the design process should be well integrated with the manufacturing process. The build orientation and character of load, as seen in the Goodman diagram in Figure 10, can be used as a tool for designing parts for fatigues. The authors prepared this diagram based on experimental data, and it is valid for steel 1.2709. SLM technology allows the manufacture of components with functional and complex internal structures, such as channels and flow-through bores, with weights decreased by up to $50 \%$.

All dual servo valve ports were printed and directly connected with the external hydraulic ports on the actuator housing by complex internal galleries, allowing full redundancy of the system and complete mechanical separation of the flow paths [42]. Changing the cross-sectional area of the internal ports enabled the packing of two hydraulic servo valves and anti-jam control sleeves into a center gland housing with an unprecedented level of integration. This approach to designing hydraulic parts could revolutionize fluid 
power systems and significantly increase their potential in the aerospace industry. The use of 3D printing allows for significant reductions in the number of parts required for larger assemblies. The manufacture of parts by means of the technology in question decreases the usage of the target material, and thus the waste material (the turnings) is reduced to a minimum.

Author Contributions: Conceptualization, K.W., J.S., and P.B.; methodology, K.W., J.S., and P.B.; software, K.W., J.S., and P.B.; validation, K.W., J.S., and P.B.; formal analysis, K.W., J.S., P.B., and P.R.; investigation, K.W., J.S., and P.B.; resources, K.W., J.S., and P.B.; data curation, K.W., J.S., and P.B.; writing - original draft preparation, K.W. and P.R.; writing-review and editing, P.R. and T.R.; visualization, K.W., J.S., P.B., and P.R.; supervision, P.B., P.R., and T.R.; project administration, P.B.; funding acquisition, P.B. All authors have read and agreed to the published version of the manuscript.

Funding: The article has been realized within the framework of the project New generation of the hydraulic cylinder FBW made with application of Additive Manufacturing and machining technology at low temperatures (cryogenics) — co-financed by the INNOLOT Program 1/1.2/2015/POIR; measure 1.2: sectoral R\&D programs 2014-2020, project No. POIR.01.02.00-00-0010/15.

Institutional Review Board Statement: Not applicable.

Informed Consent Statement: Not applicable.

Data Availability Statement: Data sharing is not applicable to this article.

Conflicts of Interest: The authors declare no conflict of interest.

\section{References}

1. Di Rito, G. Experiments and simulations for the study of temperature effects on the performances of a fly-by-wire hydraulic actuator. Proc. Inst. Mech. Eng. Part I J. Syst. Control. Eng. 2011, 225, 1195-1206. [CrossRef]

2. Zhao, Z.; Yu, X.; Zhang, Z.; Shu, W.; Li, J. Attempting AG-Doped Diamond-Like Carbon Film to Improve Seal Performance of Hydraulic Servo-Actuator. Materials 2020, 13, 2618. [CrossRef] [PubMed]

3. Di Rito, G.; Galatolo, R. Experimental assessment of the dynamic stiffness of a fault-tolerant fly-by-wire hydraulic actuator. Proc. Inst. Mech. Eng. Part G J. Aerosp. Eng. 2012, 226, 679-690. [CrossRef]

4. Garza, P.; Perinpanayagam, S.; Aslam, S.; Wileman, A. Qualitative Validation Approach Using Digital Model for the Health Management of Electromechanical Actuators. Appl. Sci. 2020, 10, 7809. [CrossRef]

5. Huang, L.; Yu, T.; Jiao, Z.; Li, Y. Active Load-Sensitive Electro-Hydrostatic Actuator for More Electric Aircraft. Appl. Sci. 2020, 10, 6978. [CrossRef]

6. Rahrovi, B.; Mehrdad, E. A review of the more electric aircraft power electronics. In Proceedings of the 2019 IEEE Texas Power and Energy Conference (TPEC), College Station, TX, USA, 7-8 February 2019.

7. Hospodka, J.; Bínová, H.; Pleninger, S. Assessment of All-Electric General Aviation Aircraft. Energies 2020, 13, 6206. [CrossRef]

8. Thapa, N.; Ram, S.; Kumar, S.; Mehta, J. All electric aircraft: A reality on its way. Mater. Today Proc. 2021, 43, 175-182. [CrossRef]

9. Vedova, M.D.L.D.; Germanà, A.; Berri, P.C.; Maggiore, P. Model-Based Fault Detection and Identification for Prognostics of Electromechanical Actuators Using Genetic Algorithms. Aerospace 2019, 6, 94. [CrossRef]

10. Chudý, P.; Tomczyk, A.; Rzucidlo, P. Safety enhanced digital flight control system. Aircr. Eng. Aerosp. Technol. 2009, 81, 416-423. [CrossRef]

11. Wang, X.; Liao, R.; Shi, C.; Wang, S. Linear Extended State Observer-Based Motion Synchronization Control for Hybrid Actuation System of More Electric Aircraft. Sensors 2017, 17, 2444. [CrossRef] [PubMed]

12. Lee, Y.-B.; Park, J.-W.; Lee, G.-C. A Study on Failure Analysis and High Performance of Hydraulic Servo Actuator. Appl. Sci. 2020, 10, 7451. [CrossRef]

13. Jani, D.B.; Ashish, S.; Aditya, S.; Yash, S.; Bishambhar, S.; Nikhil, S.; Manmohan, S. An overview on aircraft hydraulic system. Renew. Sustain. Energy Rev. 2019, 6, 29-35.

14. Han, C.; Kim, K. A Study on the Reliability and Maintainability Analysis Process for Aircraft Hydraulic System. J. Korea Soc. Syst. Eng. 2016, 12, 105-112. [CrossRef]

15. Sun, X.; Wang, X.; Lin, S. Multi-Fault Diagnosis Approach Based on Updated Interacting Multiple Model for Aviation Hydraulic Actuator. Information 2020, 11, 410. [CrossRef]

16. AF-9 Skydrol Overview, Eastman Chemical Company. Available online: https://www.eastman.com/Brands/EAS/Products/ Pages/Skydrol.aspx (accessed on 15 March 2021).

17. Helwig, A.; Müller, G.; Paul, S. Health Monitoring of Aviation Hydraulic Fluids Using Opto-Chemical Sensor Technologies. Chemosensors 2020, 8, 131. [CrossRef]

18. Hueber, C.; Horejsi, K.; Schledjewski, R. Review of cost estimation: Methods and models for aerospace composite manufacturing. Adv. Manuf. Polym. Compos. Sci. 2016, 2, 1-13. [CrossRef] 
19. Aerospace: Liebherr-First Metal 3D Printed Primary Flight Control Hydraulic Component Flies on an AIRBUS A380. Available online: https: / / rmsiberia.com/aerospace-liebherr-first-metal-3d-printed-primary-flight-control-hydraulic-component-flieson-an-airbus-a380/ (accessed on 15 March 2021).

20. Antunes, F.; Santos, L.; Capela, C.; Ferreira, J.; Costa, J.; Jesus, J.; Prates, P. Fatigue Crack Growth in Maraging Steel Obtained by Selective Laser Melting. Appl. Sci. 2019, 9, 4412. [CrossRef]

21. Cheng, C.-W.; Jian, W.-Y.J.; Makala, B.P.R. Selective Laser Melting of Maraging Steel Using Synchronized Three-Spot Scanning Strategies. Materials 2021, 14, 1905. [CrossRef] [PubMed]

22. Saracyakupoglu, T. The Qualification of the Additively Manufactured Parts in the Aviation Industry. Am. J. Aerosp. Eng. 2019, 6, 1-10. [CrossRef]

23. Kučerová, L.; Zetková, I.; Jeníček, Š.; Burdová, K. Production of Hybrid Joints by Selective Laser Melting of Maraging Tool Steel 1.2709 on Conventionally Produced Parts of the Same Steel. Materials 2021, 14, 2105. [CrossRef]

24. Jarfors, A.E.W.; Shashidhar, A.C.G.H.; Yepur, H.K.; Steggo, J.; Andersson, N.-E.; Stolt, R. Build Strategy and Impact Strength of SLM Produced Maraging Steel (1.2709). Metals 2021, 11, 51. [CrossRef]

25. Tyczyński, P.; Siemiątkowski, Z.; Bąk, P.; Warzocha, K.; Rucki, M.; Szumiata, T. Performance of Maraging Steel Sleeves Produced by SLM with Subsequent Age Hardening. Materials 2020, 13, 3408. [CrossRef] [PubMed]

26. Kleemann, E.; Dey, D.; Recksiek, M.; DaimlerChrysler Aerospace. The development of a civilian fly by wire flight control system. Proceedings of ICAS Congress ICAS, Harrogate International Conference Centre, Harrogate, UK, 7 August-1 September 2000.

27. Lu, Z.; Zhuang, L.; Dong, L.; Liang, X. Model-Based Safety Analysis for the Fly-by-Wire System by Using Monte Carlo Simulation. Processes 2020, 8, 90. [CrossRef]

28. Jacazio, G.; Gastaldi, L. Robust pressure control improves the performance of redundant fly-by-wire hydraulic actuators. Int. J. Appl. Eng. Res. 2016, 11, 8590-8597.

29. Dołega, B. Some remarks about aircraft control and navigation system as reliable fault tolerant system. Pomiary Autom. Kontrola 2011, 57, 1024-1027.

30. Dołega, B.; Rzucidło, P. Controllers for fault tolerant actuators. Aviation 2007, 11, 23-27. [CrossRef]

31. Sendeckyj, G.P. Constant life diagrams-A historical review. Int. J. Fatigue 2001, 23, 347-353. [CrossRef]

32. Jimenez-Vicaria, J.D.; Gomez-Pulido, M.D.; Castro-Fresno, D. Numerical and Experimental Evaluation of a CFRP Fatigue Strengthening for Stringer-Floor Beam Connections in a 19th Century Riveted Railway Bridge. Metals 2021, 11, 603. [CrossRef]

33. Dobrzański, L.A. Metal i ich Stopy; International OCSCO World Press: Gliwice, Poland, 2017.

34. 18 Percent Nickel Maraging Steels, Engineering Properties; Publication No. 4419; Nickel Development Institute: Toronto, CA, USA, 1976.

35. Vock, S.; Klöden, B.; Kirchner, A.; Weißgärber, T.; Kieback, B. Powders for powder bed fusion: A review. Prog. Addit. Manuf. 2019, 4, 383-397.

36. Wauthle, R.; Vrancken, B.; Beynaerts, B.; Jorissen, K.; Schrooten, J.; Kruth, J.-P.; Van Humbeeck, J. Effects of build orientation and heat treatment on the microstructure and mechanical properties of selective laser melted Ti6Al4V lattice structures. Addit. Manuf. 2015, 5, 77-84. [CrossRef]

37. Alfaify, A.; Saleh, M.; Abdullah, F.M.; Al-Ahmari, A.M. Design for Additive Manufacturing: A Systematic Review. Sustainability 2020, 12, 7936. [CrossRef]

38. Mooney, B.; Kourousis, K.I. A Review of Factors Affecting the Mechanical Properties of Maraging Steel 300 Fabricated via Laser Powder Bed Fusion. Metals 2020, 10, 1273. [CrossRef]

39. Konieczny, B.; Szczesio-Wlodarczyk, A.; Sokolowski, J.; Bociong, K. Challenges of Co-Cr Alloy Additive Manufacturing Methods in Dentistry-The Current State of Knowledge (Systematic Review). Materials 2020, 13, 3524. [CrossRef]

40. Collins, A. Servo Actuators. England Patent WO2016/075491 A1, 19 May 2016.

41. Yasa Flight Control. Available online: http://yasa-motors.com/wp-content/uploads/2017/05/FBW-brochure.pdf (accessed on 15 March 2021).

42. Warzocha, K.; Bak, P. Method for Manufacturing the Aircraft Valve Block. Poland Patent PL227484, 23 June 2017.

43. Nicolin, I.; Nicolin, B.A. The fly-by-wire system. INCAS Bull. 2019, 11, 217-222. [CrossRef]

44. Meneghetti, G.; Rigon, D.; Cozzi, D.; Waldhauser, W.; Dabala, M. Influence of build orientation on static and axial fatigue properties of maraging steel specimens produced by additive manufacturing. In Proceedings of the 3rd International Symposium on Fatigue Design and Material Defects, FDMD 2017, Lecco, Italy, 19-22 September 2017. 